\title{
Saúde digital: interseções entre a pesquisa científica e sua midiatização
}

\section{Digital health: intersections between scientific research and its mediatization}

\section{Salud digital: intersecciones entre la investigación científica y su mediatización}

\author{
Alessandra de Falco Brasileiro Lermen ${ }^{1, a}$ \\ alessandrafalco@ufsj.edu.br | https://orcid.org/0000-0001-7121-9411 \\ ${ }^{1}$ Universidade Federal de São João del Rei. São João del-Rei, MG, Brasil. \\ a Doutorado em Educação pela Universidade Estadual de Campinas.
}

\section{Resumo}

Este ensaio apresenta a relação entre as divulgações científicas e as jornalísticas sobre saúde digital, utilizando como base metodológica a midiatização e as textualidades midiáticas. Foi possível demonstrar a similaridade entre os produtos e serviços estudados/divulgados. Os temas em voga foram Internet das coisas, aplicativos, dispositivos vestíveis, Inteligência Artificial, Big Data e robótica. Enquanto nos artigos científicos são apontadas vantagens e desvantagens das aplicações tecnológicas, sendo mais críticos, na mídia especializada valorizam-se as vantagens.

Palavras-chave: Saúde digital; Pesquisa científica; Midiatização; Saúde Digital News; Exame Informática.

\begin{abstract}
This essay presents the relationship between the scientific and the journalistic articles about digital health, using as a methodological basis the mediatization and the mediatic textuality. It was possible to demonstrate the similarity between the products and services studied/disclosed. The hot topics were Internet of Things, apps, wearable devices, Artificial Intelligence, Big Data and robotics. While in the scientific articles are pointed out advantages and disadvantages of technological applications, being more critical, in the specialized media the advantages are more valued.
\end{abstract}

Keywords: Digital health; Scientific research; Mediatization; Saúde Digital News; Exame Informática. 


\section{Resumen}

Este ensayo presenta la relación entre las divulgaciones científicas y las periodísticas sobre salud digital, utilizando como base metodológica la mediatización y la textualidad mediática. Se pudo demostrar la similitud entre los productos y servicios estudiados/divulgados. Los temas en boga fueron Internet de las cosas, aplicaciones, dispositivos usables, Inteligencia Artificial, Big Data y robótica. Mientras que en los artículos científicos se apuntan ventajas y desventajas de las aplicaciones tecnológicas, siendo estas más críticas, en los medios especializados se valoran mucho más las ventajas.

Palabras-clave: Salud Digital; Investigación Científica; Mediatización; Saúde Digital News; Exame Informática.

\section{Contribuição dos autores:}

Concepção e desenho do estudo: Alessandra de Falco Brasileiro Lermen.

Aquisição, análise ou interpretação dos dados: Alessandra de Falco Brasileiro Lermen.

Redação do manuscrito: Alessandra de Falco Brasileiro Lermen.

Revisão crítica do conteúdo intelectual: Alessandra de Falco Brasileiro Lermen.

Declaração de conflito de interesses: não há.

Fontes de financiamento: não houve.

Considerações éticas: não há.

Agradecimentos/Contribuições adicionais: Joana Ziller.

Histórico do artigo: submetido: 08 ago. 2018 | aceito: 02 abr. 2019 | publicado: 28 jun. 2019.

Apresentação anterior: não houve.

Licença CC BY-NC atribuição não comercial. Com essa licença é permitido acessar, baixar (download), copiar, imprimir, compartilhar, reutilizar e distribuir os artigos, desde que para uso não comercial e com a citação da fonte, conferindo os devidos créditos de autoria e menção à Reciis. Nesses casos, nenhuma permissão é necessária por parte dos autores ou dos editores. 


\section{Introdução}

Este ensaio descreve sucintamente o cenário de tecnologias aplicadas à saúde, divulgadas por meio de artigos científicos recentes, publicados em português, e incorpora trechos de matérias jornalísticas atuais para demonstrar a relação entre as divulgações científicas e as jornalísticas sobre o tema. Adota-se como procedimento teórico metodológico a compreensão da midiatização “[...] como conceito central em uma teoria sobre a importância intensificada e mutante da mídia dentro da cultura e da sociedade [...]”.

Considera-se ainda que: "Ao tomarmos os textos jornalísticos como produtos que refletem parte daquilo que os envolve, trabalhamos com narrativas que se tornaram, por intermédio da mídia, midiatizadas. Passam, portanto, a fazer parte de uma trama social na qual estão inseridas. Não podemos ver naqueles textos um reflexo absoluto do que o envolve, um significado completo em si, mas, sim, um fragmento de uma temporalidade específica e de uma determinada trama de relações, que pode apontar determinadas construções de significado que se mostram importantes para uma pesquisa que trate da mídia como um dos atores que constrói a cena social”" .

Portanto, "[...] busca-se superar análises que observam o texto-pelo-texto, em busca de um olhar que analise o texto em seus contextos comunicativos"3, no caso específico, as inter-relações entre os artigos científicos e as divulgações midiáticas sobre o tema saúde digital, no mesmo momento histórico atual, buscando encontrar possíveis confluências. Concordando ainda com a afirmação de Bastos e Costa de que "[...] a mídia desempenha um papel crucial, mas não determinante, no fornecimento de informações necessárias para tomada de decisões sobre riscos, benefícios e opções de consumo associados aos produtos derivados da ciência e tecnologia”."

Neste cenário, optou-se também por utilizar como método a análise das textualidades midiáticas, considerando que "Lemos os textos que, de algum modo, encarnam formas de experiência. São corpos vivos"4, uma vez que se busca identificar como a ciência e a mídia estão caminhando, na maior parte das vezes, em paralelo quando o assunto é a compreensão e a divulgação da saúde digital, considerando que "[...] os textos midiáticos não vivem soltos, e se constituem em meio a processos materiais, históricos e situacionais que os conformam / os dão forma. Por um olhar comunicacional, os textos são sempre encaixados, e se explicam sucessivamente em relação a outros textos"4.

É importante ainda destacar que as pesquisadoras consideram a afirmação de Ricoeur que diz que "[...] a interpretação não é um ato sobre o texto, mas um ato do texto" $\mathrm{e}$ ainda que "[...] o que se deve, de fato, interpretar num texto é uma proposta de mundo, de um mundo tal que eu possa habitar e nele projetar um dos meus mundos possíveis. É aquilo a que eu chamo o mundo do texto, o mundo próprio a este texto único"s.

E então a pesquisa se justifica, uma vez que: "Anotar as narrativas insurgidas diante dos textos, em inúmeros momentos da pesquisa, bem como as marcas contextuais da leitura, torna-se movimento fundamental, capaz de revelar o mundo aberto pelos textos, na experiência de pesquisa. [...] Sendo assim, diante do tecido, o pesquisador torna-se atento ao processo de tecer (engendrado por si próprio, por outros sujeitos que nele habitam, por outros textos científicos, profanos, leigos)"4.

Bastos afirma que o estudo da mídia pode "[...] incluir diferentes fenômenos artísticos e discursivos - da literatura medieval do século XIX às pesquisas médicas atuais [...]”', sendo que o tema saúde digital está em voga no momento. A newsletter 'Meio de responsabilidade', de Pedro Doria - um dos principais jornalistas da área de tecnologia no Brasil -, por exemplo, incluiu desde 05 de junho de 2018 a editoria Healthtech, para abordar assuntos relacionados à inovação e à medicina, veiculada toda terça-feira. Este cenário justifica o método utilizado nesta pesquisa, uma vez que se considera a midiatização como a "[...] mudança da mídia e da comunicação, por um lado, e a mudança da cultura e da sociedade, por outro"'.

"A utilização de ferramentas tecnológicas na área da saúde está em crescente expansão. Uma das principais vantagens das intervenções em saúde por meio de aplicativos é que elas são facilmente acessíveis e utilizáveis [...]”8. Os principais temas abordados nos artigos científicos, assim como na mídia, foram: Prontuário Eletrônico do Paciente (PEP), Internet das coisas (IoT), aplicativos, dispositivos vestíveis (wearables), Inteligência Artificial (IA), Big Data e robótica. 


\section{Midiatização}

Neste estudo, considera-se a midiatização como sendo o processo pelo qual a informação, neste caso científica e especificamente sobre saúde digital, ao mesmo tempo que acontece como experiência real consolidada em fato em artigos, é transmitida pelos veículos midiáticos. Assim, assume-se "[...] não somente a vida mediada pela lógica da mídia, mas a experiência qualificada pela mídia. Implica uma nova relação do homem com o mundo, reconfigurada pelo tecnodeterminismo e pelo mercado" . É importante ressaltar também que os avanços tecnológicos não influenciam apenas mudanças no âmbito da saúde, mas também o modus operandi da mídia, reflexos da e na contemporaneidade, que originaram a "tecnocultura"

Segundo Sodré "[...] a sociedade contemporânea (dita 'pós-industrial') rege-se pela midiatização, quer dizer, pela tendência da virtualização das relações humanas"11 , esta que ocorre não apenas no âmbito do ambiente midiático, por exemplo, quando um robô controlado por Inteligência Artificial apresenta um telejornal na China $^{12}$, mas também na área da saúde, quando aplicativos nos dispositivos móveis analisam a saúde do usuário a partir da quantidade dos seus passos diários, ou do seu tempo de sono - controlados por uma análise de movimentos corporais junto aos aparelhos. Observando este cenário, a pesquisa confirma, a partir dos exemplos a seguir, que "[...] as mediações em ambiente de midiatização implicam complexos processos de negociação de sentido" 9 . Foram encontrados vestígios de um processo de midiatização específico, uma vez que os veículos de comunicação analisados, 'Saúde Digital News' e 'Exame Informática', fazem referência à realidade científica-tecnológica aplicada à saúde, que pôde ser observada a partir da relação das textualidades existentes entre os artigos científicos analisados e as publicações noticiosas divulgadas.

"Midiatização seria, assim, a crescente articulação das instituições sociais com as lógicas da mídia e, acrescentamos, em ambiente de mediação e de reflexividade, as lógicas da mídia não estão imunes às demandas sociais, que as obrigam a promover mudanças nos seus modos e formas de dar a ver as sociedades em suas contradições" ". Assim, nas notícias selecionadas foi possível observar o olhar midiático sobre o tema saúde digital, demonstrando, mais do que apenas uma representação, uma convergência com o âmbito da produção científica.

Uma das características da midiatização observada foi justamente "[...] a busca pela completude da enunciação, na tentativa jornalística de dar conta discursivamente de uma totalidade do acontecimento que préexistiria ao relato do mesmo"9. Lembrando que vivemos em uma sociedade na qual até a informação está em risco - pode ser falsa e dessa forma circular -, principalmente quando o tema envolve ciência e tecnologia, áreas atualmente em destaque quando se fala em busca por informações, ainda mais envolvendo o tema saúde. Isso posto, considerando-se ainda o percurso de um conteúdo de origem técnica, especializada, para alcançar um público leigo. Assim, os sentidos - muito novos - passam por um processo de compreensão e incorporação pelo público.

A partir do conceito de midiatização, optou-se por procurar artigos científicos por ordem de relevância no Google Acadêmico, cuja temática, buscada entre aspas, era 'saúde digital'. Na sequência, optou-se pela leitura dos resumos dos artigos e da completude daqueles cuja temática também estava exposta nos veículos de comunicação ‘Saúde Digital News' e 'Exame Informática', para, finalmente, poder comparar as temáticas em voga na Ciência e na Mídia, e encontrar possíveis convergências e/ou divergências. A principal hipótese era de que as temáticas seriam encontradas, mas com interpretações necessárias para adequação ao conteúdo midiático, como o uso de uma linguagem mais simples e sucinta - o que de fato aconteceu. A surpresa foi encontrar o conteúdo analisado produzido no âmbito da Ciência, amplamente divulgado pela mídia especializada, mesmo que com cunho mais mercadológico do que científico.

Enfim, este ensaio faz uma reflexão com base em análise bibliográfica de artigos científicos recentes sobre aplicações da saúde digital. A pesquisa foi realizada de março até julho de 2018, a partir da palavrachave 'saúde digital', considerando os artigos publicados entre 2013 e 2017, em português. No total, foram 
encontradas 113 publicações na base de dados SciELO. A mesma busca diretamente no Google Acadêmico trouxe 108 resultados. Optou-se por utilizar esta, pela similaridade dos conteúdos.

A leitura foi realizada por ordem de relevância do sistema, considerando que esta não é uma pesquisa quantitativa, mas sim qualitativa. Também dentro dos artigos - foram excluídas teses, dissertações, monografias e livros - foi procurado, como palavra-chave, 'saúde digital', a partir de uma leitura scanner. Foram analisadas nove publicações científicas e foram feitas incorporações de textos jornalísticos publicados nos sites 'Saúde Digital News', especializado no tema (total de 49 publicações observadas), e 'Exame Informática', especializado em tecnologia (total de 10 publicações observadas), pesquisados durante o período de março até abril de 2018.

\section{Aplicações da saúde digital e sua midiatização}

Um dos principais temas abordados no site 'Saúde Digital News' durante o período de análise foi o uso do Prontuário Eletrônico do Paciente (PEP), citado em 10 publicações. Este que "[...] é uma ferramenta mais eficaz que o prontuário em papel: proporciona melhor comunicação entre a equipe multiprofissional, aumentando a qualidade do tratamento do paciente e a organização das informações" ${ }^{\prime 3}$. Um exemplo cita que o Hospital Beneficência Portuguesa de São Paulo conectou o banco de sangue ao PEP, e outro afirma que o registro digital das informações do paciente pode "[...] assegurar que as informações coletadas em diferentes consultas possam ser usadas por outros médicos, permitindo o acompanhamento de tratamentos" ${ }^{14}$.

Na pesquisa realizada por Rondina e colaboradores "Foi comparado um hospital do interior do estado de São Paulo com dados de implantação e utilização do prontuário eletrônico do paciente de 13 instituições de saúde brasileiras. As principais vantagens apontadas pelas instituições analisadas foram: facilidade na consulta de dados e redução no tempo de atendimento. A principal desvantagem foi a resistência dos profissionais de saúde ao uso de sistemas eletrônicos. [...] As principais desvantagens estão intimamente ligadas à falta de capacitação para o uso adequado do software"13.

Outro exemplo do site 'Saúde Digital News' cita apenas as vantagens do uso do PEP como: fácil atualização e acesso aos dados dos pacientes pela web, possibilidade de manter as informações salvas de forma mais segura e de compartilhamento, acesso imediato aos diversos dados (atendimentos, internações, histórico do paciente, resultados e laudos de exames, alergias, vacinas tomadas e medicamentos utilizados), facilidade para tomada de decisões tanto pelo médico quanto pelo paciente, melhora na qualidade e agilidade no atendimento, redução de pedido de exames, melhora no tratamento de doenças e no acompanhamento para prevenção e diminuição do risco de prescrições indevidas. Ainda em termos administrativos, aborda a normatização e padronização graças à integração via sistema online, o que diminui erros e retrabalhos e eleva a produtividade ${ }^{11}$.

A partir do contexto de midiatização, é possível afirmar que, pelo veículo de comunicação 'Saúde Digital News' ser especializado no setor e ter um viés afirmado de marketing, cria um ambiente a partir das narrativas midiáticas de positivismo em relação ao tema, utilizando como estratégia dar visibilidade às qualidades de produtos e serviços, muitas vezes sem sequer citar pontos negativos ou questionáveis. Os artigos científicos sobre o assunto colaboram para confirmar ou contestar o entorno sociocultural desta mídia pesquisada, que é propriedade do grupo TI Inside Online, que afirma ser a principal fonte de consulta sobre tendências e inovações em tecnologia e negócios do mundo digital.

Outro tema de destaque, a IoT, envolve utilizar uma gama de recursos tecnológicos para conectar dispositivos e pessoas, que podem inclusive ser aplicados à saúde. Oliveira e Silva ${ }^{16}$ abordam o monitoramento do corpo em tempo real, o que também é citado em matéria do 'Saúde Digital News' sobre idosos que utilizam sistemas de alerta para evitar locomoções desnecessárias e reduzir tempo de filas ${ }^{17}$. 
"Com os pacientes conectados a sensores para medir sinais vitais e outras informações biométricas, os problemas podem ser rapidamente diagnosticados, um serviço de saúde de melhor qualidade pode ser prestado [...]”16. Matéria publicada na editoria de Ciência da 'Exame Informática' apresenta um aparelho para ser acoplado ao dente para monitorizar tudo o que se come, bebe e fuma, criado por pesquisadores da Tuffts University School of Engineering ${ }^{18}$. "Para melhor compreensão da importância do IoT na saúde podemos simular o caso de um paciente que sofre de bulimia (distúrbio de alimentação) em um hospital ou uma monitoração residencial, os sensores no ambiente do paciente podem detectar o aumento da temperatura do corpo ou pressão sanguínea, ou até mesmo o odor de vômitos, os dados obtidos dessas atividades podem proporcionar informações de valor no diagnóstico e gerenciamento de doenças"15.

Oliveira e Silva também citam aplicativos “[...] que permitem tanto ao paciente compreender seu estado e agir sobre ele, quanto alertar profissionais sobre a proximidade de eventos agudos"15, como é o caso do aplicativo Ticket Fit, apresentado no 'Saúde Digital News', que é plataforma focada em qualidade de vida e bem-estar ${ }^{19}$. Os autores abordam ainda as possibilidades de diagnóstico e acompanhamento remoto de pacientes, utilizando os dispositivos vestíveis (wearables) como sensores, para diagnosticar doenças cardíacas, monitorar a ingestão de medicação para asma e até a qualidade do ar ou a taxa de glicose, sendo que os dados são enviados para os smartphones ${ }^{15}$.

“Com ferramentas baseadas em aplicativos e tecnologias vestíveis para monitorar a saúde e até mesmo realizar seus próprios exames, os pacientes finalmente poderão realizar autodiagnósticos de uma grande variedade de condições em sua própria casa, sem precisar ir a um consultório ou hospital”20. Outro exemplo é um adesivo, que pode monitorar os níveis alcoólicos em apenas 8 minutos, alertando o usuário para não dirigir ${ }^{21}$. Young ${ }^{22}$ também aborda emplastos e adesivos que apresentam resultados de medidas fisiológicas (pulso, frequência respiratória, temperatura, eletrocardiograma) para checar pressão sanguínea ou nível de glicose para os diabéticos.

O autor também cita um aplicativo capaz de detectar alterações no tom de voz, em uma conversa utilizando um smartphone, que pode prever uma internação “[...] com uma exacerbação de insuficiência cardíaca congestiva até 10 dias antes de sua ocorrência. Com isso, você poderia telefonar para sua mãe de manhã e ela dizer que se sente bem, mas o aplicativo diz que ela precisa tomar $20 \mathrm{mg}$ a mais de furosemida!”22.

A Exame Informática também aborda outra solução: “[...] para analisar o comportamento do coração do utilizador através de pulseiras com sensores e que ajudam a prever, em tempo útil, a perda de concentração e vigilância dos motoristas de autocarros. As pulseiras usadas são da Microsoft e enviam os dados para o smartphone e para os servidores da Optimizer, desencadeando depois a alarmística necessária”²3.

Em 2016, as pesquisadoras Souza e Silva publicaram um artigo sobre aplicativos que tinham como objetivo colaborar com a capacidade funcional de idosos, quando encontraram oito aplicativos para o sistema operacional Android, disponíveis na Play Store, para gerenciar medicações, como o Medisafe que: "Gerencia medicamentos através de lembretes, sonoros ou não, do horário do uso, acompanhamento de outros parâmetros de saúde como glicemia e PA, lembretes para reposição de receita, listagem dos medicamentos e relatórios de progresso" 24 .

"Os aplicativos que ajudam a gerenciar medicamentos, por exemplo, podem trazer grande contribuição na correta adesão ao tratamento medicamentoso, uma vez que possibilitam não só que o idoso seja informado do horário de uso e lembrado da correta prescrição, mas também que algum cuidador ou profissional de saúde faça a correta programação do aplicativo e supervisione o uso, além de possibilitar acesso a informações por parte de profissionais de saúde durante possíveis atendimentos"24.

O site 'Saúde Digital News' divulgou diversas matérias entre março e abril de 2018 sobre o uso de aplicativos na saúde, desde o "uber da medicina”, possibilitando que usuários fossem lembrados de suas consultas e levados até elas sem atrasos ${ }^{14,25}$; até uma empresa que oferece terapia por meio de aplicativo: 
“Um dos grandes diferenciais da OrienteMe é que o paciente pode enviar mensagens de texto, áudio, imagem e vídeo a qualquer momento e o terapeuta responderá todos os dias úteis dentro de 24 horas”26.

“Os aplicativos para celulares na área da saúde são outras inovações que têm aumentado exponencialmente, não só os destinados ao público em geral, mas também os especializados para os profissionais de saúde, como forma de melhor capacitar e/ou de otimizar o fluxo de informação com as unidades centrais de saúde”27. Em especial ao aplicativo que possibilita a locomoção de pacientes, o artigo científico de Neto e colaboradores aborda esta temática citando o uso de ferramentas como o Uber original e outro aplicativo, o Lyft 15, em casos de “[...] transporte de pacientes em caráter não emergencial [...] e se não é possível familiares realizarem esse transporte, muito menos o desembolso com motoristas particulares ou simplesmente táxis"28.

Amorim e outros autores também estudaram 25 aplicativos focados na saúde e cuidado com idosos especificamente: “Os aplicativos objetivam a prática de exercício físico, a prevenção ou detecção de quedas, a estimulação cognitiva, a busca de profissionais ou serviços, o auxílio ao cuidado de idosos e a divulgação de informações sobre saúde e sobre doenças e tratamentos. Esses recursos podem trazer grande contribuição à saúde e ao aperfeiçoamento do cuidado ao idoso, sendo um instrumento de monitoramento, informação e promoção de hábitos saudáveis"8.

O uso dos aplicativos traz vantagens tanto para o paciente, quanto para o médico, que pode utilizá-los na forma de orientações para prescrição ou busca de evidências científicas ${ }^{29}$ e ainda "[...] poderão analisar rapidamente os exames ou registros dos pacientes usando seu dispositivo móvel, deixando mais tempo do seu dia de trabalho para atendimentos aos pacientes"20. Young aborda ainda equipamentos que podem ser plugados nos smartphones, como os para análise de sondas de ultrassom: "Existem mais de 160.00o aplicativos anunciados nas lojas Apple e Android como estando relacionados à atenção à saúde”22 e atualmente empresas os testam.

$\mathrm{O}$ atendimento online utilizando aplicativos e sites também é abordado tanto em artigos científicos quanto nas matérias jornalísticas, inclusive com ênfase para sua eficácia tão boa quanto um atendimento presencial. Como citado acima, no site 'Saúde Digital News' há um exemplo de notícia que aborda um aplicativo que possibilita ao usuário falar com um terapeuta quando e onde quiser, através de mensagens de texto, vídeo ou áudio, sem limite para envio e recebimento de colocações ${ }^{26}$. Young ${ }^{22}$ cita uma biblioteca virtual com perguntas e respostas sob curadoria médica, garantindo que "em torno de 10\% das consultas presenciais podem ser realizadas via biblioteca e um adicional de 20-30\% via uma combinação de $e$-mail/texto, telefone e vídeo consultoria”.

Uma pesquisa, divulgada também em 2016, aborda os dispositivos vestíveis (wearables) que servem “[...] para o controle do usuário sobre sua própria saúde, através do monitoramento de dados emitidos pelo corpo humano"14. Os dispositivos vestíveis como relógios conectados aos smartphones “[...] são integrados ao corpo e capazes de processar dados emitidos pelo organismo do sujeito e transformá-los em informações, permitindo, ainda, um fluxo de comunicação constante e instantânea”29.

Este caso pode ser visto em exemplo no 'Saúde Digital News', que apresenta uma plataforma que "[...] permite identificar automaticamente o nível de emoção e estresse em cada ligação que o usuário fizer, oferecendo uma análise de quais dias o usuário estava mais tranquilo ou estressado. Por meio dos sensores de movimento do celular, o aplicativo identifica em qual período o usuário estava dormindo e, assim, determina quantas horas ele descansou por noite. Dessa forma, o sono, que é um importante regulador de saúde, será monitorado diariamente e de forma automática"3o.

"Um dos exemplos mais comuns do uso de tecnologias de comunicação e informação, associado aos cuidados com a saúde, consiste no monitoramento de informações relativas ao consumo alimentar e à rotina de exercícios físicos

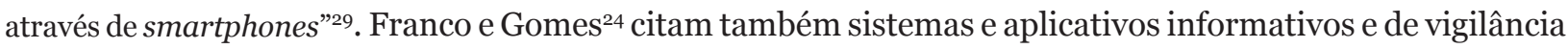
participativa para monitorar doenças como gripe, dengue e zika, inclusive sendo utilizados de forma sazonal em grandes eventos como o Mundial de Futebol de 2014 (Saúde na Copa) e os Jogos Olímpicos de 2016 (Guardiões da Saúde). 
Apesar da consideração da importância desses aplicativos, no caso acima também é feita uma crítica, uma vez que um único aplicativo que concentrasse as informações sobre todas essas doenças seria mais útil, principalmente utilizando dados relacionados à geolocalização. Segundo Fantoni "[...] a evolução das tecnologias digitais no campo da saúde permite explorar os dados constantemente emitidos pelo corpo humano de forma mais profunda, rastreando informações que, no passado, poderíamos obter somente através de exames médicos”²9.

Exemplo do 'Saúde Digital News' é justamente sobre uma plataforma que possibilita o monitoramento completo da saúde: "A plataforma Sharecare recolhe informações completas de saúde, desde a altura e peso até a taxa de glicose, e permite a integração com diversos dispositivos inteligentes, como pulseiras e relógios que monitoram atividades. Além disso, o aplicativo traz a funcionalidade chamada RealAge, método que leva em consideração cada taxa de saúde e hábito diário (tabagismo, consumo de álcool, prática de exercícios, alimentação, entre outros) para mensurar a idade real da pessoa, que pode ser maior ou menor do que sua idade biológica. A partir do resultado, a ferramenta fornece soluções que o usuário poderá adotar para diminuir sua idade real e ficar 'mais jovem' a cada dia, contribuindo com sua saúde como consequência"3o.

Fantoni ainda cita o termo empregado por Rettberg ${ }^{29}$, "laços afetivos", que são gerados quando da quantificação dos dados compilados pelos dispositivos vestíveis, referente ao sono, por exemplo, o que pode levar o usuário a se sentir satisfeito, já que "[...] índices e gráficos satisfatórios configuram um incentivo para a manutenção de práticas saudáveis"29. O exemplo do Sharecare destaca uma especial atenção a isso, ao afirmar que o seu principal recurso é o “[...] GreenDay, uma premiação baseada nos hábitos de saúde, que é representada por um coração verde a ser preenchido conforme o cumprimento desses hábitos. Para completar o coração, é necessário realizar diariamente pelo menos oito dos fatores considerados importantes para ter uma vida saudável"30.

$\mathrm{O}$ artigo de Fantoni também dá exemplos de wearables, como o seguinte aplicativo: "Preso à roupa por um grampo, o sensor identifica alterações na respiração do usuário e envia uma notificação para seu smartphone: caso reconheça tensão ou estresse na forma como o sujeito está respirando, Spire sugere que ele pare por alguns instantes e respire fundo [...]”29 e o OvuRing que identifica o período fértil e envia um aviso para o smartphone. Já Franco e Gomes ${ }^{27}$ criticam a quantidade de ferramentas disponíveis, nem sempre funcionais. Em suas considerações abordam os dispositivos vestíveis capazes de monitorar informações como a pressão sanguínea, índices de glicose e colesterol, ou até rastrear dados sobre saúde mental a partir da medida de níveis de estresse ou produtividade, por exemplo.

O uso de Tecnologias da Informação e Comunicação também foi apresentado pela mídia como uma preocupação, não apenas com o uso de aplicativos, mas também de Inteligência Artificial (IA). Exemplo do 'Saúde Digital News' revela que "Alguns hospitais brasileiros já utilizam AI em aparelhos que captam sinais vitais do paciente e enviam automaticamente para o prontuário (sem intervenção humana). No Reino Unido esse tipo de tecnologia remota permitiu a redução de $52 \%$ das internações de idosos" ${ }^{2}$.

Big Data foi outro tema abordado na mídia e em artigos científicos, como citado no mesmo exemplo acima que apresenta uma ferramenta capaz de "[...] identificar até 10 níveis de dor, avaliar agitação e sedação apenas por análise facial” ${ }^{2}$. Franco e Gomes abordam o projeto de 'ciência cidadã' de vigilância participativa, como mencionado anteriormente, e também o 'Radar Cidadão'; assim como o caso de utilização de dados disponíveis na Internet pelos usuários, como o exemplo do Google Trends, para mostrar tendências - horas corretas, horas defasadas - sobre a gripe ${ }^{27}$.

Funciona com "[...] a detecção digital de doenças utilizando a vigilância participativa, em que o cidadão é convidado a reportar voluntariamente informação sobre o seu estado de saúde, por meio do preenchimento de um questionário de sintomas via Internet, permitindo complementar a informação recolhida tradicionalmente pelas unidades de saúde. [...] o Google Flu Trends, em vários anos conseguiu estimar razoavelmente bem a intensidade da epidemia de gripe, mas noutras épocas fez sobrestimações por utilizar os mesmos algoritmos de anos anteriores, sem ter em conta outros fatores como o aumento de pesquisas relacionadas com a gripe devido à maior ênfase nas notícias sobre a doença”² 
Outro tema citado é a robótica. No curso de medicina da Universidade Federal de Minas Gerais (UFMG), por exemplo, são realizadas "[...] atividades de ensino com simulação em manequins robotizados ou semirrobotizados”33. Exemplo no site 'Saúde Digital News', apresenta o investimento de R\$ 11 milhões de um hospital em robô cirúrgico que "[...] possibilita aos cirurgiões acessar locais considerados difíceis em cirurgias complexas, realizar incisões mais precisas e contar com visão 3D ampliada, o que permite aos especialistas terem melhor percepção de profundidade e imagem cristalina" 34 .

Ainda em relação às críticas da aplicação de tecnologias à saúde, considera-se que é preciso melhorar a interoperabilidade, ou seja, "[...] a capacidade de integrar esses dispositivos ao fluxo de trabalho de cuidados de saúde” ${ }^{\text {" }}$. Como é afirmado neste exemplo do 'Saúde Digital News' “[...] não adianta muito os médicos, clínicas, hospitais etc. serem extensamente informatizados quanto à documentação centrada no paciente, se ela ficar restrita $\mathrm{e}$ não puder ser compartilhada entre os diferentes provedores"35. Retrato de que a mídia trata “[...] de certa maneira, de um lócus de reverberação e negociação da vida social" ${ }^{\prime 6}$.

Em seu artigo, Young afirma que, apesar de todos os avanços relacionados à aplicação de novas tecnologias na saúde, "[...] a prática médica tem sido lenta em se adaptar a este progresso" ${ }^{22}$. Em contrapartida, o autor continua, o próprio paciente passa a ter o controle de sua saúde com o uso de tecnologias personalizadas - o que é confirmado em exemplos do 'Saúde Digital News'37,38 que abordam a autonomia dos pacientes e o acesso remoto às suas informações $24 \mathrm{~h}$-, mas, ao mesmo tempo, fala de um estudo que revela que "[...] os pacientes com 'tecnologia' se sentiam mais isolados socialmente do que aqueles sem ela”22.

Young ainda cita produtos e práticas que não foram abordados nos artigos jornalísticos, mas é preciso ressaltar que este é um artigo traduzido e algumas inovações apresentadas fazem parte de um contexto internacional. "De balanças e esfigmomanômetros WiFi às lentes de contato Google que medem continuamente níveis de glicose e o estetoscópio CliniCloud Bluetooth com algoritmo detector de pneumonia (https:// clinicloud.com), tanto pacientes como cuidadores podem se envolver no manejo de sua saúde. Existe até mesmo uma fralda que avisará seu smartphone quando precisar ser trocada. O 'propeller inhaler' [aplicativo conectado ao inalador] está transformando o tratamento de problemas respiratórios (https://www. propellerhealth.com). Ao registrar onde e quando os inaladores estão sendo utilizados, os pacientes estão conectados com seus cuidadores e entre si”22.

\section{Conclusões}

Pelo cenário apresentado neste artigo, convergências entre o conteúdo divulgado pelas pesquisas e aquele midiatizado confirmam que os dois mundos culturais, o da ciência e o da mídia, estão caminhando lado a lado. Isso inclusive em relação à divulgação do que é e de como pode ser aplicada determinada tecnologia à saúde, porém, com poucos artigos ou matérias jornalísticas dando ênfase para casos práticos, para as vozes dos pacientes que poderiam confirmar, ou não, a validade de tais aplicações - o que seria papel do jornalismo.

Outro detalhe é que raramente foram abordadas falhas ou questionamentos em relação aos usos das tecnologias, como se os dispositivos e técnicas apresentadas fossem ideais, quiçá perfeitos. Sendo assim, é possível concordar com Latour que afirma que "Nós, leigos, pessoas não pertencentes à área ou simples cidadãos, seríamos incapazes de discutir sentenças [...]. Mas, uma vez que outras pessoas discutam essas coisas [...], somos conduzidos, sem esforço nenhum”39. A midiatização do tema saúde digital confirma a pretensão de eficácia da aplicação de tecnologias na área, divulgada a partir da produção científica.

Tanto nos sites ‘Saúde Digital News' e da 'Exame Informática' quanto nos artigos científicos, o ponto de vista ideológico predominante é de que as tecnologias aplicadas à saúde vêm para colaborar com as atividades da área, o que pode influenciar leitores, pacientes ou médicos em busca de ajuda ou suporte. Apesar de ser função da mídia mostrar os dois lados da notícia, destacam-se as vantagens. Já os artigos científicos são mais críticos. Em ambos os casos, no jornalismo e na ciência, as textualidades circulantes retratam um mundo atual de conexão entre saúde e tecnologias, numa sociedade cunhada pelas possibilidades de interação entre homem e máquina. 


\section{Referências}

1. Hjarvard S. Midiatização: teorizando a mídia como agente de mudança social e cultural. Matrizes [Internet]. 2012 jan./jun. [citado em 2018 ago. 06];5(2):53-91. Disponível em: https://bit.ly/2EfNTdw

2. Vieira LA. Memória e midiatização: livros-reportagem como guardiões da memória de um tempo? In: Carvalho CA, organizador. Midiatização e textualidades: dimensões teóricas e aplicações empíricas. Belo Horizonte: PPGCOM/UFMG; 2017. p. 126-143.

3. Bastos A, Costa VS. Midiatização na ciência: a controvérsia da "pílula do câncer". In: Carvalho CA, organizador. Midiatização e textualidades: dimensões teóricas e aplicações empíricas. Belo Horizonte: PPGCOM/UFMG; 2017. p. 287-317.

4. Antunes $\mathrm{E}_{\text {; }}$ Mafra $\mathrm{R}$, Jáuregui $\mathrm{C}$. Mídia em trânsito, mídia em transe: textualização, epifania e distanciação. In: Leal B, Carvalho CA; Alzamora G, organizadores. Textualidades midiáticas. Belo Horizonte: PPGCom/ UFMG; 2018. p. 35-57.

5. Ricoeur P. Do texto à acção: ensaios de hermenéutica II. Porto: Res; 1991.

6. Bastos MT. Medium, media, mediação e midiatização: a perspectiva germânica. In: Junior Janotti J, Mattos MA, Jacks N. Mediação e Midiatização. Salvador: EDUFBA; 2012. p. 53-77.

7. Hepp A. As configurações comunicativas de mundos midiatizados: pesquisa da midiatização na era da "mediação de tudo". Matrizes [Internet]. 2014 jan./jun. [citado em 2018 ago. 06];8(1): 45-64. Disponível em: https://www.revistas.usp.br/matrizes/article/download/82930/85964. doi: http://dx.doi. org/10.1177/0267323113501148

8. Amorim DNP, Sampaio LVP, Carvalho GA, Vilaça KHCC. Aplicativos móveis para a saúde e o cuidado de idosos. Reciis [Internet]. 2018 jan./mar. [citado em 2018 ago. 06];12(1):58-71. Disponível em: https://www. reciis.icict.fiocruz.br/index.php/reciis/article/view/1365. doi: http://dx.doi.org/10.29397/reciis.v12i1.1365

9. Mattos MA Janotti Junior J, Jacks N, organizadores. Mediação e midiatização. Bahia: EDUFBA, 2012. Disponível em: http://books.scielo.org/id/k64dr

10. Moraes D, organizador. Sociedade midiatizada. Rio de Janeiro: Mauad X, 2018.

11. Sodré M. Eticidade, campo comunicacional e midiatização. In: Sociedade midiatizada. Rio de Janeiro: Mauad X, 2018.

12. Lima R. China tem robô controlado por IA como âncora de telejornal [Internet]. [Curitiba]: Megacurioso; 2018 [citado em 2019 abr. 23]. Disponível em: https://bit.ly/2vpF6R7

13. Rondina JM, Rodrigues YP, Canêo, PK, Campos MS. Prontuário eletrônico do paciente: comparação de um hospital de ensino com outras instituições de saúde. RESDITE [Internet]; 2017 jan./ago. [citado em 2018 ago. 06]:2(3):41-50. Disponível em: https://bit.ly/2L34NS9

14. Conselho Federal de Medicina regulamenta aplicativos para chamar médicos em casa [Internet]. [São Paulo]: Saúde Digital News; 2018 [citado em 2018 ago. 06]. Disponível em: https://bit.ly/2W7E4EX

15. Silva GB. O bom uso da informação pode salvar vidas [Internet]. [São Paulo]: Saúde Digital News; 2018 [citado em 2018 ago. 06]. Disponível em: https://bit.ly/2ZEXEuG

16. Oliveira RS, Oliveira JLS. A internet das coisas (IOT) com enfoque na saúde. Tecnol Projeção [Internet]; 2017 [citado em 2018 ago. 06];8(1):77-85. Disponível em: http://revista.faculdadeprojecao.edu.br/ index.php/Projeca04/article/view/824

17. Relatório mostra como TICs podem melhorar a qualidade de vida dos idosos na AL [Internet]. [São Paulo]: Saúde Digital News; 2018 [citado em 2018 ago. 06]. Disponível em: https://bit.ly/2L3mQaM

18. Um wearable que consegue detectar o que se come, bebe e fuma. Exame Inform [Internet]. 2018 [citado em 2018 ago. 06]. Disponível em: https://bit.ly/2UE1ws0

19. Ticket usa recursos digitais para lançar novos serviços médicos [Internet]. [São Paulo]: Saúde Digital News; 2018 [citado em 2018 ago. 06]. Disponível em: https://bit.ly/2V2xRh5

20. Setor de saúde será totalmente digitalizado até 2030 para garantir operação dos serviços [Internet]. [São Paulo]: Saúde Digital News; 2018 [citado em 2018 ago. 06]. Disponível em: https://bit.ly/2IH4vOI

21. Tatuagem temporária pode ser usada para monitorizar níveis de álcool. Exame Inform [Internet]. 2018 [citado em 2018 ago. 06]. Disponível em: https://bit.ly/2Pyy59E 
22. Young AJ. Novas tecnologias e medicina de família. Rev Bras Med Fam Comunidade [Internet]. 2017 jan./dez. [citado em 2018 ago. 06];12(39):01-06. doi: https://doi.org/10.5712/rbmfc12(39)1465

23. Pulseiras que monitorizam comportamento cardíaco do utilizador. Exame Inform [Internet]. 2018 [citado em 2018 ago. 08]. Disponível em: https://bit.ly/2UJHhcm

24. Souza CM, Silva AN. Aplicativos para smartphones e sua colaboração na capacidade funcional de idosos. RESDITE [Internet]. 2016 jan./jul. [citado em 2018 ago. 08];1(1):06-19. Disponível em: http:// periodicos.ufc.br/resdite/article/view/4681/3484

25. Uber lança serviço voltado para profissionais da saúde e pacientes. [São Paulo]: Saúde Digital News; 2018 [citado em 2018 ago. 08]. Disponível em: https://bit.ly/2Py8Zrv

26. OrienteMe oferece terapia por meio de aplicativo. [São Paulo]: Saúde Digital News; 2018 [citado em 2018 ago. 08]. Disponível em: https://bit.ly/2vx07tj

27. Franco AO; Gomes MGM. Desafios e oportunidades na saúde digital. Cad Saúde Pública [Internet]; 2017 nov. [citado em 2018 ago 08];33(11):02-03. Disponível em: https://bit.ly/2GKt7UM. doi: https://doi. org/10.1590/0102-311X00090417

28. Neto Leal OB, Albuquerque J, Souza WV, Cesse E, Cruz OG. Inovações disruptivas e as transformações da saúde pública na era digital. Cad Saúde Pública [Internet]; 2017 [citado em 2018 ago. 08];33(11);01-04. Disponível em https://bit.ly/2ZuFThk. doi: https://doi.org/10.1590/0102-311X00005717

29. Fantoni A. Dispositivos wearable para o campo da saúde: reflexões acerca do monitoramento de dados do corpo humano. Temática [Internet]; 2016 jan. [citado em 2018 ago. 08];XII(01):185-198. Disponível em: https://bit.ly/2Wc2TQ9

30. Sharecare investe em plataforma de saúde e bem-estar no Brasil [Internet]. [São Paulo]: Saúde Digital News; 2018 [citado 2018 ago. 08]. Disponível em: https://bit.ly/2vqPzM3

31. Rettberg JW. Seing ourselves through technology: how we use selfies, blog and wearable devices to see and shape ourselves. New York: Palgrave Macmillan; 2014.

32. IA e Big Data cortam 35\% dos custos operacionais na área de saúde, revela estudo [Internet]. [São Paulo]: Saúde Digital News; 2018 [citado em 2018 ago. 08]. Disponível em: https://bit.ly/2GGSipX

33. Reis ZSN, Melo MCB, Corrêa EJ, Pereira AK, Santos DB, Alves HJ. Tecnologias digitais para o ensino em saúde: relato de experiências e a convergência para o projeto AVAS21. RESDITE [Internet]; 2016 jan./ jul. [citado em 2018 ago. 08];1(1):69-76. Disponível em: https://bit.ly/2XSxZNe

34. Hospital Santa Catarina investe R\$11 milhões em robô cirúrgico [Internet]. [São Paulo]: Saúde Digital News; 2018 [citado em 2018 ago. 08]. Disponível em: https://bit.ly/2XToMEd

35. Três tecnologias de futuro na Saúde [Internet]. [São Paulo]: Saúde Digital News; 2018 [citado em 2018 ago. 08]. Disponível em: https://bit.ly/2HaZFG9

36. Alzamora G, Ziller J, D'Andrea C. Mídia e dispositivo: uma aproximação à luz de Michel Foucault. In: Leal B, Carvalho CA, Alzamora G, organizadores. Textualidades midiáticas. Belo Horizonte: PPGCom/UFMG; 2018. p. $59-81$.

37. Santos C. CIOs devem estar atentos para adoção de redes 5 G na Saúde [Internet]. [São Paulo]: Saúde Digital News; 2018 [citado em 2018 ago. 08]. Disponível em: https://bit.ly/2LaMudO

38. ABIMED cria grupo de trabalho para acelerar adoção de tecnologias 4.0 na área da Saúde [Internet]. [São Paulo]: Saúde Digital News; 2018 [citado em 2018 ago. 08]. Disponível em: https://bit.ly/2LkBF9g

39. Latour B. Ciência em ação. Como seguir cientistas e engenheiros sociedade afora. São Paulo: Unesp; 2011. 